\title{
Energy consumption, operating cost and treatment of tea effluent using electrocoagulation
}

\author{
Makau Francis Kalulu ${ }^{1}$. Paul Sang Magut ${ }^{2}$, Njenga Mburu ${ }^{3}$, \\ ${ }^{I}$ Engineering Dedan Kimathi University of Technology \\ ${ }^{2}$ Department of Chemistry Dedan Kimathi University of Technology \\ ${ }^{3}$ Engineering Dedan Kimathi University of Technology \\ Corresponding Authors: Makau Francis Kalulu
}

Received: 17/01/2017; Revised:12/12/2018_ Accepted:11/02/2019

\begin{abstract}
The effluents from tea processing plants are characterized by a strong colour and high turbidity due to the presence of large amounts of suspended solids, dissolved organic matter and inorganic wastes which include detergents, grease/waste oil from machine parts. These altogether poses an environmental and legal challenge calling for appropriate means of treatment. In this regard the study was designed to evaluate energy consumption, operating cost in treatment of tea effluent using electrocoagulation method at optimum conditions of electrode distance $6 \mathrm{~mm}$, electrolysis time $18 \mathrm{~min}$, Current intensity $250 \mathrm{~mA}$ The study adopted an experimental research design. From the study findings Energy consumption was found to be $0.0018 \mathrm{Kwh} / \mathrm{m}^{3}$ at an operating cost of $U S \$ 0.004179032 / \mathrm{m}^{3}$ at laboratory scale. The findings further showed that at industrial scale design parameters such as Diameter, height, electrode spacing, retention time, current intensity and reactor volume were $100 \mathrm{~cm}, 150 \mathrm{~cm}, 60 \mathrm{~mm}, 59.94$ minutes, 25 Amps and $1.2 \mathrm{~m}^{3}$ respectively which equally reduces COD and Colour removal at $99.43 \%$ and 98.62 with energy consumption of $4.8 \mathrm{Kwh} / \mathrm{m}^{3}$ at an operating cost US $\$ 0.744$. In conclusion EC provides the most feasible alternative for treatment of tea effluent with a view of COD reduction and colour removal.
\end{abstract}

Key words: Energy Consumption, Electrocoagulation And Operating Cost

\section{Background of the study}

Globally the removal of pollutants from industrial waste remains the most essential in terms of protection of health as well as the environment. Some of the pollutants have heavy metals which pose serious health hazard, and are environmentally-unfriendly because they are not biodegradable and tend to accumulate in living organisms (Saha \& Sanyal, 2010). Wastewater regulations were established to minimize human and environmental expo- sure to hazardous chemicals which limits on the types and concentration of heavy metals and organic wastes that may be present in the discharged wastewater (Barakat, 2011).This altogether calls for knowledge on the cost effective and environmental friendly techniques of treating waste water.

Like other biomass residues, tea waste is an unused resource and poses increasing disposal problems (Arvanitoyannis \& Varzakas, 2008). According to Maghanga, Segor, Etiégni and Lusweti, (2009) during the cleaning operations, flushing steps in operations and production processes, $18-20 \mathrm{~m}^{3}$ of water is used per cleaning operation releasing large amounts of tea factory effluents. These effluents are characterized by a strong colour and high turbidity due to 
the presence of large amounts of suspended solids, dissolved organic matter and inorganic wastes which include detergents, grease/waste oil from machine parts (Ochari, 2010).

Recently, numerous approaches have been studied for the development of cheaper and more effective technologies, both to decrease the amount of wastewater produced and to improve the quality of the treated effluent (Barakat, 2011). It is therefore important to note that the overall treatment cost of industrial waste water varies, depending on the process employed and the local conditions. In general, the technical applicability, simplicity and cost-effectiveness are the key factors in selecting the most suitable treatment of industrial waste water (Kurniawan, 2006) . Socio-cultural and environmental objectives that are recognized to be of the same importance as the economic objective in selecting the optimal wastewater treatment alternative (Ellis and Tang, 1991 and 1994) cited in (Karimi, Mehrdadi, Hashman, Nabi, \& Tavakoli, 2011). Physical methods such as ion exchange, reverse osmosis and electro dialysis have proved to be either too expensive or inefficient to remove cadmium from water (Vasudevan \& Lakshmi, 2011).

Literature surveys indicates that electrocoagulation is an efficient process for different types of waste, e.g. soluble oils, liquids from food, textile industries and effluents from the paper industry (Calvo, et al., 2003; Carmona, et al., 2006). During the past few years, EC has been proposed as an effective method for treating many types of effluents such as wastewater charged with heavy metals (Kumar et al., 2004), natural water charged with Fluor (Emamjomeh \& Sivakumar, 2006), surface water (Lai \& Lin, 2006.), suspended solids, oil and fat in restaurant wastewater, black liquor from paper industry, and cigarette factory wastewater. All these investigations demonstrated that EC could achieve a significant reduction of major pollutants and has become of growing interest for the industrial scale (Zaieda \& Bellakhala, 2009). The operating cost includes material (mainly electrodes) cost, electrical energy, cost of labour, maintenance and other cost. The later cost items are largely independent of the electrode material (Kobya et al., 2006). Besides EC as waste water treatment technique is an empirically optimized process that requires more fundamental knowledge on operating cost and energy consumption to realize its full potential. This without prejudice have motivated the current study to evaluate energy consumption, operating cost and treatment of tea effluent using electrocoagulation at Emrok tea factory.

\subsection{Objectives}

i To evaluate the energy consumption at the optimal electrocoagulation operating conditions in the treatment of tea effluent at Emrok tea factory.

ii To analyse the operating cost at the optimal electrocoagulation operating conditions in the treatment of tea effluent at Emrok tea factory.

\section{Methodology}

\subsection{Research Design}

A research design includes the structure of a study and the strategies for conducting that study (Leedy \& Jeanne, 2013). This study adopted an experimental research design which is a systematic and scientific approach to research in which the researcher manipulates one or more variables, controls and measures any change in other variables (Oskar, 2018 ). Experimental designs offer the best method available to researchers to be able to investigate causality due to 
the high degree of control (Robin, 2009). In experimental research designs subjects are always both randomly allocated into the different groups and randomly sampled. Statistical techniques are used in the development of an adequate functional relationship between variables of interest. In experimental research designs regression considers the effect upon one variable when another is held fixed at each of several levels (Cook \& Campbell, 1979).

\subsection{Energy consumption}

The energy consumption during the EC process was determined as follows:

Energy consumption $=\frac{V \times I \times T}{60 \mathrm{~V}}$

Where Energy Consumption V, I, t and V are energy consumptions $\left(\mathrm{kWh} / \mathrm{m}^{3}\right), \mathrm{V}$ is the voltage (Volt), I is the current (Ampere), $\mathrm{t}$ is EC time (s) and $\mathrm{V}$ is volume of treated water in $\mathrm{m}^{3}$

Electrode Consumption (wear) $=\frac{I \times t \times M_{w}}{z \times F}$

Where $\mathrm{F}$ is faradays constant $(96,485 \mathrm{C} / \mathrm{mol}), \mathrm{Mw}$ is molar mass of the iron $(55.845 \mathrm{~g} / \mathrm{mol})$ and $\mathrm{z}$ is the number of electron transfer $\left(\mathrm{Z}_{\mathrm{Fe}}\right.$ : 2) (Ozyonar \& Karagozoglu, 2011).

\subsection{Calculation of operating cost.}

EC operational cost was determined according (Geraldino, et al., 2015).

Operating cost $(o c)=a \cdot c_{e n}+b \cdot c_{e l}$

$\mathrm{a}=$ energy cost

$c_{e n}=$ energy consumption

$\mathrm{b}=$ cost of the plate

$\mathrm{C}_{\mathrm{el}}=$ electrode consumption

Where, Energy consumption and Electrode consumption are consumption quantities per $\mathrm{M}^{3}$ of treated wastewater (Kobya et al., 2006).

\subsection{Industrial scale design parameters}

The industrial scale parameters were adopted from (Sawhney, 2008). The effluent flow rate will be determined by

$Q_{h}=\frac{Q_{P}}{24} m^{3} / h r$

$Q_{h}$ : Hourly Flow rate

$Q_{P}$ : Daily Flow rate of effluent

To determine industrial velocity the continuity equation of fluid flow was adopted

$Q_{p}=A_{p} V_{P}$

$V_{P}=\frac{Q_{P}}{A_{P}}$

Where

$Q_{p}$ : rate of effluent flow

$A_{p}$ : Cross sectional area of fluid flow

$V_{P}$ : Velocity of fluid flow 
Geometric Similarity was used to determine the prototype height and diameter. Geometric Similarity: implies similarity of shape between the model and prototype the model is an exact replica of the prototype having identical shape but smaller in size. The model and prototype have same ratio for all corresponding linear dimensions.

$$
\frac{h_{p}}{h_{m}}=\frac{w_{p}}{w_{m}}=\frac{L_{p}}{L_{m}}=\frac{D_{p}}{D_{m}}=L_{r}
$$

Where

$h_{p}$ : Height of prototype

$h_{m}$ : Height of the model

$W_{p}$ : Width of the prototype

$W_{m}$ : Width of the model

$L_{p}$ : Length of the prototype

$D_{p}$ : Diameter of the prototype

$D_{m}$ : Diameter of the model

$L_{r}$ : Length scale ratio

Batch (industrial scale) Retention Time $T_{r}$ (Froude's Model Law)

$T_{r}=\sqrt{L_{r}}=\frac{T_{p}}{T_{m}}$

$T_{r}=\frac{T_{p}}{T_{m}}$

$T_{r}$ : Time scale ratio

$T_{P}$ : Retention time of the prototype

$T_{m}$ : Retention time of the model

Industrial Scale (prototype) Voltage

the voltage of model (lab scale) is $P_{m}$ and prototype $P_{p}$

$L_{r}=\frac{P_{p}}{P_{m}}$

$P_{P}=L_{r} \times P_{m}$

\section{FINDINGS}

3.1 Evaluation of energy consumption and operating cost at the optimal electrocoagulation operating conditions.

\subsubsection{Energy consumption}

The energy consumption during the EC process was determined as follows: in this study at optimum conditions of electrode distance $6 \mathrm{~mm}$, electrolysis time $18 \mathrm{~min}$, Current intensity 250 $\mathrm{mA}$ the energy consumption was found to be $0.0018 \mathrm{kwh} / \mathrm{m}^{3}$ with a removal efficiency $98.62 \%$ COD and $99.43 \%$ Colour. This denotes low energy consumption with higher removal efficiency 
using iron electrodes in tea effluents as compared to the findings of Zaroual et al (2009) who found out that a treatment efficiency of $91 \%$ could be completed with an energy consumption of $3.536 \mathrm{kWh} / \mathrm{m}^{3}$.

Energy consumption was determined According to equation 3.11.1 below during the EC process.

$$
\text { Energy consumption }=\frac{V \times I \times T}{60 \mathrm{~V}}
$$

The energy consumption at optimum electrode distance $6 \mathrm{~mm}$, electrolysis time $18 \mathrm{~min}$, and Current intensity $250 \mathrm{~mA}$ (laboratory scale) was therefore

$$
\begin{aligned}
=\frac{24 \times 0.25 \times 18}{60 \times 1000} & \\
& =0.0018 \mathrm{kwh} / \mathrm{m}^{3}
\end{aligned}
$$

\subsubsection{Electrode consumption (wear)}

To calculate the maximum amount of electrode material that was consumed during the EC process, in which the molar mass of iron is $55.845 \mathrm{~g} \mathrm{~mol}^{-1}$, faradays constant $96,485 \mathrm{C} / \mathrm{mol}$, electrolysis time $18 \mathrm{~min}$, and the oxidation number of the element is 2 . From equation 3.11 .3

$$
\begin{array}{r}
\text { Electrode Consumption }=\frac{I \times t \times M_{w}}{z \times F} \\
=\frac{18 \times 60 \times 0.25 \times 55.845}{2 \times 96485} \\
=7.8 \times 10^{-2} \mathrm{gFe}
\end{array}
$$

\subsubsection{Operating cost at laboratory scale}

In this study the operating cost using iron electrodes at optimum electrode distance $6 \mathrm{~mm}$, electrolysis time $18 \mathrm{~min}$, and Current intensity $250 \mathrm{~mA}$ the cost wasUS\$0.004179032 / $\mathrm{m}^{3}$ which removed (98.62) \% COD and (99.43) \% Colour. This compares fairly with the findings of Drogui et al (2009) who found that using the optimum conditions to remove color $(97 \%)$ and COD (77\%) it would cost $\$ 0.29 \mathrm{USD} / \mathrm{m}^{3}$ of wastewater. This result showed that the EC process for the treatment of tea effluent under optimum conditions is quite economical. This result is in agreement with (Ozyonor \& Karagozoglu, 2011).

OC of the batch reactor in the EC system was calculated using eqn.3.12.1 a formular adopted from (Geraldino, et al., 2015). The cost of a $\mathrm{kg}$ of iron plate is US\$ 0.25 , but the mass estimated cost of a plate $(200 \mathrm{~g})$ is US\$ 0.05 . Therefore,

Where

$$
O C=a \cdot c_{e n}+b \cdot c_{e l}
$$

$\mathrm{a}=$ energy cost is US\$ 0.1550178

$c_{e n}=$ energy consumption is $0.0018 \mathrm{kwh}$

$\mathrm{b}=$ cost of the plate $(200 \mathrm{~g})$ US $\$ 0.05$

$\mathrm{C}_{\mathrm{el}}=$ electrode consumption is $0.78 \mathrm{~g} \mathrm{Fe}$

$$
\left(0.0018 \frac{k w h}{m^{3} x 0.1550178}\right)+\left(7.8 \times 10^{-2} x 0.05\right)=U S \$ 0.004179032 / m^{3}
$$




\subsubsection{Industrial scale design parameters}

The industrial scale parameters were adopted from (Sawhney, 2008)

Daily Flow rate of Emrok effluent $Q_{P}=20 \mathrm{~m}^{3}$

Hourly Flow rate of Emrok effluent $Q_{h}$

$$
\begin{gathered}
Q_{h}=\frac{Q_{P}}{24} \mathrm{~m}^{3} / h r \\
Q_{h}=\frac{20 M^{3}}{24} \\
=0.83 \mathrm{~m}^{3} / h r
\end{gathered}
$$

Cross sectional area of the industrial scale pipe

$$
\begin{gathered}
\text { Area }=\frac{\pi D^{2}}{4}=\frac{\pi \times 0.1016^{2}}{4} \\
A=0.008107 M^{2}
\end{gathered}
$$

From continuity equation:

$$
\begin{gathered}
Q_{p}=A_{p} V_{P} \\
V_{P}=\frac{Q_{P}}{A_{P}} \\
=\frac{0.83 \mathrm{M}^{3} / \mathrm{hr}}{0.008107 \mathrm{~m}^{2}}=102.79 \mathrm{~m} / \mathrm{hr}
\end{gathered}
$$

Or$$
=0.0286 \mathrm{~m} / \mathrm{s}
$$$$
v_{p}=0.0286 \mathrm{~m} / \mathrm{s}
$$

From Geometric Similarity:

$$
\frac{h_{p}}{h_{m}}=\frac{w_{p}}{w_{m}}=\frac{L_{p}}{L_{m}}=\frac{D_{p}}{D_{m}}=L_{r}
$$

From Froude's Model Law

$$
L_{r}=\frac{100}{10}=10
$$

From Velocity scale ratio:

$$
\begin{gathered}
F_{\text {Prototype }}=F_{\text {model }} \\
V_{r=\sqrt{L_{r}}} \\
v_{r}=\sqrt{10}=3.337
\end{gathered}
$$

$$
\begin{gathered}
v_{r}=\frac{v_{p}}{v_{m}} \\
v_{m}=\frac{v_{p}}{v_{r}} \\
v_{p}=0.0286 \mathrm{~m} / \mathrm{s} \\
v_{r}=3.337 \\
v_{m}=\frac{0.0286}{3.333} \\
\text { velocity of the } \operatorname{model}\left(v_{m}\right)=0.0086 \mathrm{~m} / \mathrm{s}
\end{gathered}
$$

Also using geometric similarities to establish the height of prototype 


$$
\begin{gathered}
L_{r}=\frac{h_{p}}{h_{m}} \\
10=\frac{h p}{15} \\
h_{p}=(10 \times 15) \mathrm{cm}=150 \mathrm{~cm} \\
h_{p}=150 \mathrm{~cm}=1.5 \mathrm{~m} \\
\text { Reactor volume }\left(R_{v}\right)=\frac{\pi D^{2}}{4} \times h_{p} \\
\frac{3.142 \times 10^{2}}{4} \times 1.5=1.17 \approx 1.2 \mathrm{~m}^{3}
\end{gathered}
$$

Batch (industrial scale) Retention Time $T_{r}$ (Froude's Model Law)

$$
\begin{gathered}
T_{m}=18 \mathrm{~min} \\
L_{r}=3.337 \\
T_{r}=\sqrt{L_{r}}=\frac{T_{P}}{T_{m}} \\
T_{r}=\frac{T_{P}}{T_{m}}
\end{gathered}
$$

$$
T_{P}=18 \times 3.33=59.94 \mathrm{~min}
$$

Time To process prototype (industrial scale) effluent at $\mathrm{Q}=Q_{P}=20 \mathrm{~m}^{3}$

$$
\begin{gathered}
1.2 \mathrm{~m}^{3} \rightarrow 60 \mathrm{~min} \\
20 \mathrm{~m}^{3} \rightarrow ? \\
\frac{20 \times 60}{1.2 \times 60}=16 \mathrm{hr}
\end{gathered}
$$

\section{Computation of prototype (industrial scale) current intensity}

Prototype: model (Ratio 10:1)

$$
\text { if (model) : }(20 \times 4.6) \mathrm{cm} \times 2 \rightarrow 250 \mathrm{~mA}
$$

Industrial scale (Prototype): $(200 \times 46) \mathrm{cm} \times 2 \rightarrow$ ?

$$
=25 \mathrm{~A} \frac{200 \times 46 \times 250 \times 2}{20 \times 4.6 \times 2}=25000 \mathrm{~mA} / \mathrm{cm}^{2}
$$

Distance between the electrodes (industrial scale): Where $\mathrm{L}$ is distance between electrodes

$$
L_{r}=\frac{L_{p}}{L m}
$$

But for a model (laboratory scale), to get optimal efficiency, $L=6 \mathrm{~mm}$

Industrial Scale (prototype) Voltage

$$
\begin{aligned}
L_{P} & =L_{r} \times L_{m} \\
& =6 \times 10 \\
& =60 \mathrm{~mm}
\end{aligned}
$$

Let the voltage of model (lab scale) be $P_{m}$ and prototype $P_{p}$ but $P_{m}=24 v$

Industrial Scale (prototype) $P_{P}=10 \times 24$

$$
\begin{gathered}
L_{r}=\frac{P_{p}}{P_{m}} \\
P_{P}=L_{r} \times p_{m}
\end{gathered}
$$

$$
=240 \mathrm{~V}
$$




\subsubsection{Industrial scale Energy Consumption:}

It therefore implies that if Emrok tea factory adopts EC process at an industrial scale the energy consumption shall be:

The energy consumption at its current flow rate $(\mathrm{Q})$ of $20 \mathrm{~m}^{3}$ shall be

Electrode consumption

$$
\frac{240 \times 25 \times 16}{20000}=4.8 \mathrm{kwh} / \mathrm{m}^{3}
$$

\subsubsection{Industrial operating cost}

$$
\frac{1 \times 25 \times 55.845}{2 \times 96485}=7.2 \times 10^{-3} \mathrm{gFe}
$$

$$
(4.8 \times 0.1550178)+\left(7.2 \times 10^{-3} \times 0.05\right)=U S \$ 0.744
$$

This implies that if Emrok adopts an EC system at flow rate of $20 \mathrm{~m}^{3}$ daily, the operating cost of the batch reactor in would translate to US\$ 0.744 monthly the company would spend US $\$ 22.32$ Monthly expenditure on energy

Yearly expenditure on energy

$$
0.744 U S D \times 30=U S \$ 22.32
$$

\subsection{Conclusion}

$$
U S \$ 22.32 \times 12=U S \$ 267.84
$$

The energy consumption was found to be $0.0018 \mathrm{Kwh} / \mathrm{m}^{3}$ at an operating cost of $U S \$ 0.004179032 / \mathrm{m}^{3}$ at laboratory scale with a removal efficiency $98.62 \%$ COD and $99.43 \%$ Colour. This would translate to energy consumption at $4.8 \mathrm{Kwh} / \mathrm{m}^{3}$ and operating cost of $U S \$ 0.744$ at a flow rate of $20 \mathrm{~m}^{3}$ industrial scale at the sampled factory, Emrok. Using optimized EC with a view of balancing energy consumption and operational cost was found to be feasible for tea effluent treatment. This argument is further supported by the comparative analysis between EC and the method of waste treatment used by Emrok would translate to an increase of profit margin to $4.56 \%$. This added to the un quantified benefits in terms of environmental and social gains of EC justifies its adoption in an industrial scale.

\section{References}

Arvanitoyannis, I. S., \& Varzakas, T. H. (2008). Vegetable waste treatment:comparison and critical presentation of methodologies. Crit. Rev. Food Sci. Nutr., 48, 205-247.

Barakat, M. (2011). New trends in removing heavy metals from industrial wastewater. Arabian Journal of chemistry, 4, 361-377.

Calvo, L., Paternotte, G., Valentin, G., Rostan, A., \& Lapicque, F. (2003). An electrocoagulation unit for the purification of soluble oil waste of high COD. 22 (1), 57-65.

Carmona, M., Khemis, M., Leclerc, J., \& Lapicque, F. (2006). A Simple Model to predict the removal of oil suspensions from water using the electrocoaguration technique. 61,12371246.

Cook, T., \& Campbell, D. (1979). Quasi-experimentation: Design and analysis issues for field settings. Chicago: Rand McNally.

Emamjomeh, M., \& Sivakumar, M. (2006). An empirical model for defluoridation by batch monopolar electrocoagulation/flotation process. 131, 118-125. 
Karimi, R., Mehrdadi.N., Hashman, S., Nabi, G., \& Tavakoli, R. (2011). Selection of wastewater treatment process based on the analytical hierarchy process and fuzzy analytical hierarchy process methods. Int .Journal Sci Tech , 8(3), 267-280.

Kurniawan, T. (2006). Physico-chemical treatment techniques for wastewater laden with heavy metals. Chemical engineering journal, 118, 1-2, p. 83-98.

Leedy, P. D., \& Jeanne, E. O. (2013). Practical Research: Planning and Design. Tenth edition. MA: Pearson. Boston: MA: Pearson.

Maghanga, J., Segor, F. K., Etiégni, L., \& Lusweti, J. (2009). Electrocoagulation Method For Colour Removal In Tea effluent: A Case Study Of Chemomi Tea Factory In Rift Valley,Kenya. 23 (3),371-381.

Ochari, F. (2010). design a proper functioning waste water treatment lagoon system for treatment of tea factory effluent before being released to the environment. Unpublished thesis University of Nairobi, Civil Engineering.

Oskar, B. (2018 ). Experimental Research. Retrieved from https://explorable.com/experimentalresearch Assesed on 21/1/2018

Ozyonar, F., \& Karagozoglu, B. (2011). Operating cost analysis and treatment of domestic waste water by Electrocoagulationusing Aluminium electrodes. Polish journal of environmental studies , 20(1), 173-179.

Robin, B. (2009). Research Methods Experimental Design. Retrieved from http://www.floppybunny.org/robin/web/virtualclassroom/chap16/s1/sembk2.pdf

Saha, P., \& Sanyal, S. (2010). Assesment of removal of cadmium present in wastewater using soil admixture membrane desalination . 259, 131-139.

Sawhney, G. (2008). Fundamentals of fluid mechanics. New Delhi: International Publishing House Pvt Ltd.

Vasudevan, S \& Lakshmi, J. (2011). Effects of alternating and direct current in electrocoagulation processon the removal of cadmiumfrom water a novel approach. Sep purity Unit technology, 80, 643-651.

Zaieda, M., \& Bellakhala, N. ( 2009). Electrocoagulation treatment of black liquor from paper industry. In J. Mater. 